\title{
Chemical Composition and Purification of Pyroligneous Liquor from Eucalyptus Wood
}

Raquel Silveira Ramos Almeida*, Marcel Miranda Taccini, Luiz Fernando de Moura, Udemison Luis Ceribelli, José Otávio Brito

Univerity of São Paulo/ESALQ, Department of Forest Science, Brazil

*Corresponding author: Raquel Silveira Ramos Almeida, Henraq Consultoria e Treinamento Ltd a-Al. Bauru, Brazil

Submission: 梅 February 17, 2018; Published: 侮 March 23, 2018

Abstract

The objective of this research was to analyze the chemical composition and to evaluate possible purification processes (Figure 1) of the pyrolysis condensed phase of eucalyptus wood (pyroligneous liquor) to remove toxic substances. The experiment was based on three processes:

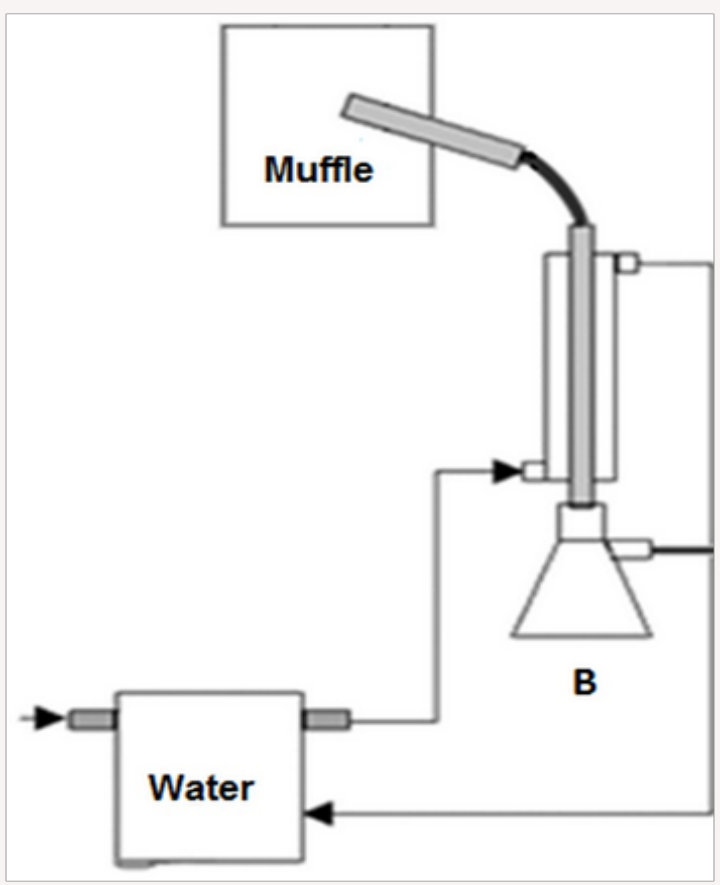

a) Simple distillation (Group 1)

b) Distillation through a still head containing charcoal (Group 2) and

c) Distillation using activated charcoal in the liquor while simultaneously passing the generated gas through a still head with activated charcoal (Group 3).

The gravimetric yield and the chemical composition of the distilled and the original pyroligneous liquors were determined through gas chromatography-mass spectroscopy. It was observed that the Group 3 distillation had the highest influence on the chemical composition of the obtained product and was also the most effective process in removing one of the most toxic compounds from the pyroligneous liquors: the 2, 6-dimetoxyphenol. No differences in gravimetric yield were observed among the processes studied.

Keywords: Botanicals; Efficacy; Synthetic pesticide; Pest; Maize

Abbreviations: CRD: Completely Randomised Design; OPMVs: Open Pollinated Maize Varieties; ARDA: Agricultural Rural Development Authority; OPv: Open Pollinated varieties 


\section{Introduction}

In the pyrolysis process, biomass is decomposed using heat while controlling the airflow. The process consists of a series of complex reactions in which the heat splits the molecular structure of the biomass, yielding solid, liquid and gaseous carbon compounds. One of the applications of pyrolysis is in the production of charcoal, where the process is known as carbonization. In the most of the applications of this process, part of the introduced wood is burnt to generate the energy to maintain the temperature. In Brazil, the wood carbonization is usually performed as a manual process, in masonry ovens. Almost all the 10 million tons of charcoal produced annually in Brazil (the world's biggest producer with about $30 \%$ of the total) is obtained in this form.

Brazilian charcoal is used in diverse segments of industry (siderurgy, metallurgy, cement etc), as well as for urban and agricultural residential use, with the siderurgical sector being the most important [1]. The technology used to obtain charcoal in Brazil discards many chemical components, most of the time via the emission of gases to the atmosphere. The global overall result of the emission of these gases is important, as much for their environmental impact as for the possible discovery of chemical products to add value to charcoal production. According to [2], the by-products arising from the carbonization process can be classified into three main groups: particulate materials, non condensable gases and condensable organic compounds.

The particulate material is composed of leached ashes, particles of charcoal and soot that are removed from the stream bed of carbonization inside micron scale drops of tar. The non condensable gases, in turn, are essentially $\mathrm{CO}_{2}, \mathrm{CO}, \mathrm{H}_{2}$ and $\mathrm{CH}_{4}$, whereas the condensable organic compounds consist of a group of organic compounds in varied chemical segments. The carbonization smoke contains toxic by-products, such as polycyclic aromatic hydrocarbons, that have mutagenic and cancer causing effects $[2,3]$. Taking into account the afore-mentioned aspects, the objective of this work was to analyze the chemical composition of and evaluate some purification processes for the condensed gases of the pyrolysis of eucalyptus wood (pyroligneous liquor) in attempt to remove toxic substances.

\section{Materials and Methods}

\section{Distillation and collection of products}

Original pyroligneous liquor (OPL) of the carbonization of the eucalyptus wood was used for the experiments. It was obtained from a charcoal producer in a tibia region, State of [4], Brazil (commercial production). The sample was collected from the chimney of brick kilns, while the temperature of the emitted smoke was between 80 and $120^{\circ} \mathrm{C}$. The wood used in the carbonization was Eucalyptus sp (probably E. saligna) aged 5 to 8 years, with moisture content between 20 and $25 \%, 1.10 \mathrm{~m}$ length and $20 \mathrm{~cm}$ diameter. The product was stored for 3 years aiming to separate the residual oily upper layer (light oil) and the bottom decanted layer (tar). The middle part was regarded as the pyroligneous extract itself [1].
The experiment evaluated three liquor distillation processes with three repetitions for each one:

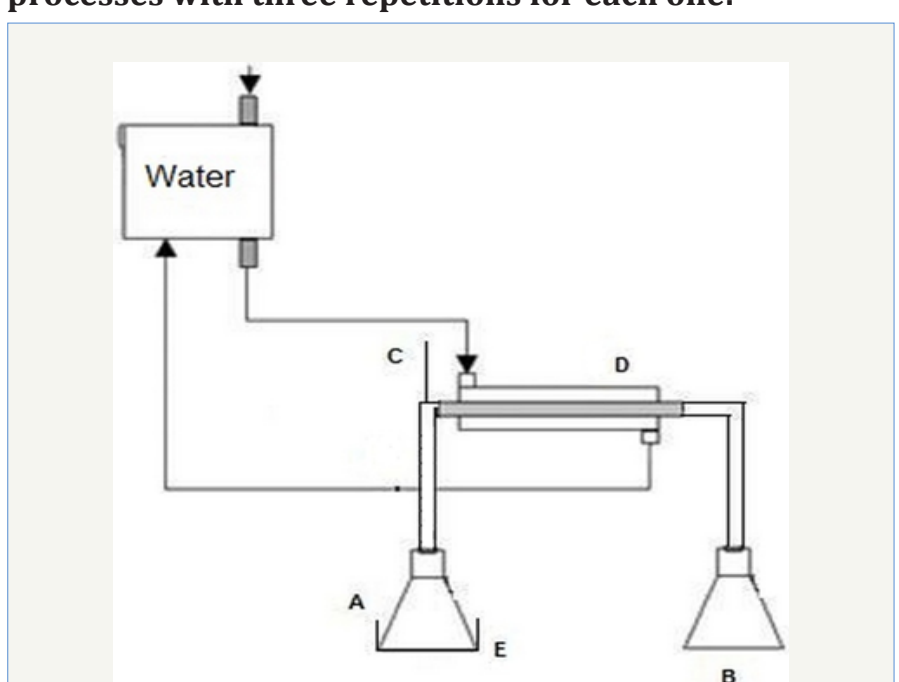

Figure 2: Process of Simple Distillation - Group 1.

A and B: Still pot entrance of the original pyroligneous liquor and collection of the distilled, respectively; C: Thermometer

D: Condenser

E: Heating blanket

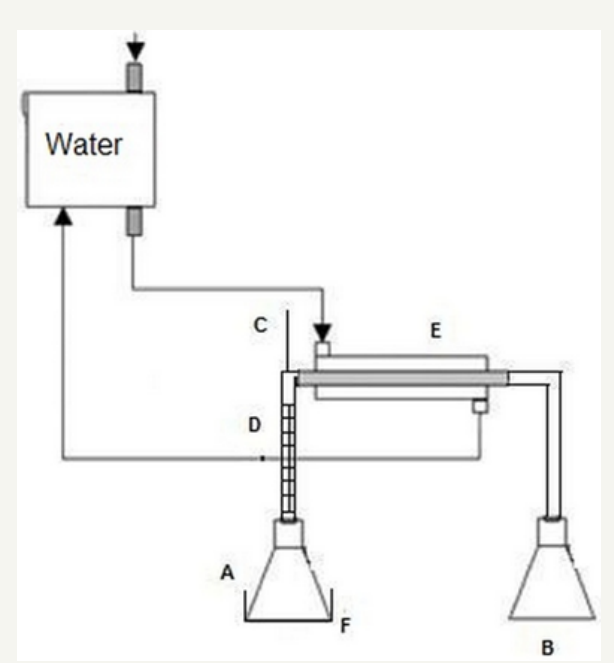

Figure 3: Process of Simple Distillation with still head containing charcoal- Group 2.

A and B: Still pot entrance of the original pyroligneous liquor and the collection of the distilled one, respectively

C: Thermometer

D: Hempel still head

E: Condenser

F: Heating blanket

Group 1 (PSD) Simple Distillation - consisted of a simple laboratory distillation unit, where a $250 \mathrm{ml}$ still pot of distillation was connected to a condensing set, collecting the distilled sample. The still pot was placed on an electric heating blanket and a thermometer was used for temperature control (Figure 2). Group 2 (PDC) Distillation through a still head containing charcoal - as in the Group 1 project -, with the addition of a Hempel still head 
connected to the still pot. The still head was prepared with the wadding of 6 bags of filter paper, containing 12g on average in the total of granulated activated charcoal (Figure 3). Group 3 (PDCC) Distillation with direct addition of $5 \mathrm{~g}$ of activated charcoal in the liquor, simultaneously passing the generated gas through the still head with activated charcoal similar to the Group 2. All experiments were performed on $180 \mathrm{~g}$ of pyroligneous liquor in the distillation still pot at a temperature of $100{ }^{\circ} \mathrm{C}$ for an average of 1.5 hours. This time was sufficient to finalize the liquid phase in the still pot. All the experiments were carried through at atmospheric pressure. The water temperature of the condenser was $25^{\circ} \mathrm{C}$.

\section{Mass balance and tar and distilled pyroligneous liquor yield calculation}

At the end of the distillation, the tar and the distilled pyroligneous liquor were weighed, so the gravimetric yield could be calculated. The tar gravimetric yield corresponds to the relation between the tar weight and the original pyroligneous liquor weight (Equation 1). The gravimetric yield of pyroligneous liquor distilled gave the percentile difference of the tar level in relation to the original liquor (Equation 2).

Where: $\mathrm{RGA}=$ tar gravimetric yield (\%), PLP = original pyroligneous liquor weight $(\mathrm{g})$ and $\mathrm{PA}=$ tar weight $(\mathrm{g})$

Where: RGLD = gravimetric yield of the distilled pyroligneous liquor (\%) and RGA = tar gravimetric yield (\%)

\section{Qualitative analysis of the original and distilled pyroligneous liquor}

To identify the chemicals in the original pyroligneous liquor and the distilled compounds obtained, the material was analyzed using a gaseous chromatograph connected to the mass spectrometer (GC/ MS) using a TRACE GC Ultra, Thermo brand equipped with DSQII. A silica capillary column $(30 \mathrm{~m} \times 0.30 \mathrm{~mm}$ ID x $0.25 \mathrm{um})$ was used. The temperature was programmed initially for $40{ }^{\circ} \mathrm{C}(3 \mathrm{~min})$ and then increased at a rate of $15^{\circ} \mathrm{C}$ min- 1 to $270{ }^{\circ} \mathrm{C}$ ( 6 min). Helium was used as a carrier gas. The volume injection was in split mode at $250{ }^{\circ} \mathrm{C}$. The interface temperature was $270{ }^{\circ} \mathrm{C}$. The split flow was $24 \mathrm{ml} / \mathrm{min}$ and the split ratio was 20 . The data was processed using Excalibur software. The produced pyroligneous liquors were compared to identify any possible qualitative discrepancies between compounds in each experimental group.

\section{Results and Discussion}

\section{Results of the mass balance}

The results of the mass balance are shown in (Table 1). Comparative analyses of the data were conducted using ANOVA ( $\alpha$ $=0.05$ ) and Turkey's test for multiple comparisons among means. No significant differences between the processes regarding tar or the distilled yields were observed $(p>0,01)$. The F-test indicated no statistical differences for the gravimetric yields of pyroligneous $(\mathrm{p}=0.6801)$ and charcoal $(\mathrm{p}=0.0971)$ at the different heating rates applied.
Table 1: Mass balance of the distillations.

\begin{tabular}{|c|c|c|c|}
\hline Group & Distillation & RGA (\%) & RGLD (\%) \\
\hline \multirow{3}{*}{1} & 1a & 0.58 & 99.42 \\
& 1b & 0.21 & 99.79 \\
& 1c & 0.86 & 99.14 \\
\hline \multirow{2}{*}{2} & 2a & 1.01 & 98.99 \\
& 2b & 0.26 & 99.74 \\
& 2c & 0.46 & 99.54 \\
\hline \multirow{3}{*}{3} & 3a & 4.29 & 95.71 \\
& 3b & 1.11 & 98.89 \\
& 3c & 0.26 & 99.74 \\
\hline
\end{tabular}

Where: $\mathrm{RGA}=$ tar gravimetric yield $(\%)$ and $\mathrm{RGLD}=$ gravimetric yield of the distilled pyroligneous liquor (\%).

\section{Analysis results of the pyroligneous liquor}

The analysis of the original pyroligneous liquor demonstrated the presence of an oxygenated component range (carboxylic acids, esters, ethers and ketenes). Moreover, phenol, guaicol and phenol derivatives were detected, similar to $[4,5,7]$. In general terms, some chemical compounds identified in the chromatograms were the same for all the evaluated liquors. However, the compounds butyrolactone and maltol, present in the original pyroligneous liquors, were not found in the distilled liquors.

Table 2: Chemical compounds present in the pyroligneous liquor.

\begin{tabular}{|c|c|c|c|c|}
\hline \multirow{2}{*}{ Chemical Compounds } & \multicolumn{4}{|c|}{ Experimental Groups } \\
\cline { 2 - 5 } & OPL & PDS & PDC & PDCC \\
\hline Methanol & 1 & 1 & 1 & 1 \\
\hline Methyl acetate & 2 & 2 & 2 & 2 \\
\hline Acetic acid & 3 & 3 & 3 & 3 \\
\hline 1-Hydroxy,2-propanone & 4 & 4 & 4 & 4 \\
\hline 1-Hydroxy,2-butanone & 5 & 5 & 5 & 5 \\
\hline 3-Furaldeyde & 6 & 6 & 6 & 6 \\
\hline Butyrolactone & 7 & nd & nd & nd \\
\hline 5-Methyl, 2-furaldeyde & 8 & 8 & 8 & 8 \\
\hline Phenol & 9 & 9 & 9 & 9 \\
\hline Corilon & 10 & 10 & 10 & 10 \\
\hline 4-Methylphenol & 11 & 11 & 11 & 11 \\
\hline 4-Methoxyphenol & 12 & 12 & 12 & 12 \\
\hline Maltol & 13 & nd & nd & nd \\
\hline 2-Methoxy, 4-Methylphenol & 14 & 14 & 14 & 14 \\
\hline 2,6-Dymethoxyphenol & 15 & 15 & 15 & nd \\
\hline
\end{tabular}

where: $\mathrm{OPL}=$ Original pyroligneous liquor; $\mathrm{PDS}=$ Simple Distillation; $\mathrm{PDC}=$ Distillation through a still head containing charcoal; $\mathrm{PDCC}=$ Distillation with direct addition of $5 \mathrm{~g}$ of activated charcoal in the liquor, simultaneously passing the generated gas through the still head with activated charcoal and nd $=$ not detected

This evidence can be better visualized in (Table 2), which summarizes the chemical components in the chromatograms of the (Figures 4-7). It must be emphasized that a chromatogram for each 
experimental group has been displayed, identifying only the 15 most representative components in terms of percentile concentration, due to the fact that there was no qualitative variation among the pyroligneous liquors produced in the carbonizations presented in the same experimental group. There were differences in chemical composition among the distillation processes tested, where Group 3 (PDCC) had fewer chemical tar components.

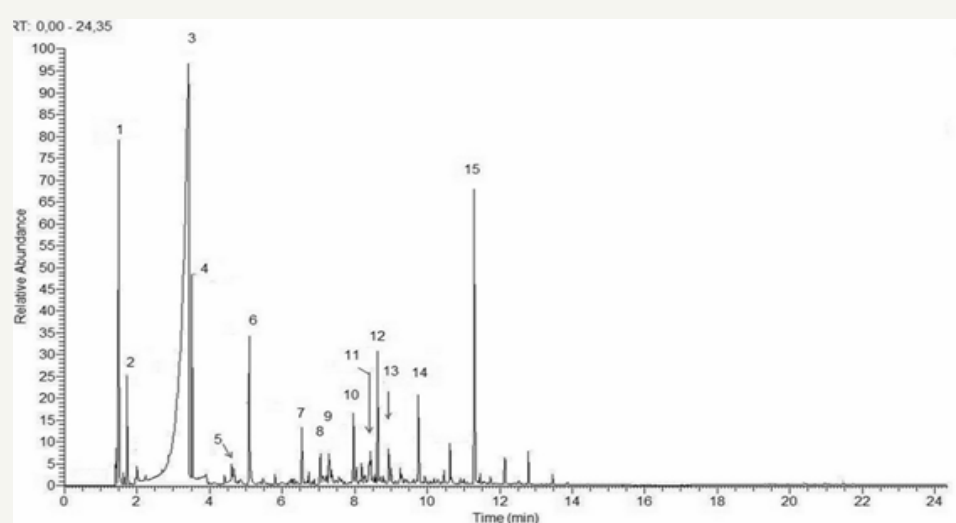

Figure 4: Chromatogram of original pyroligneous liquor- OPL.

Chromatogram of original pyroligneous liquor-OPL. The numbers on the peaks correspond to the chemical components listed in (Table 2).

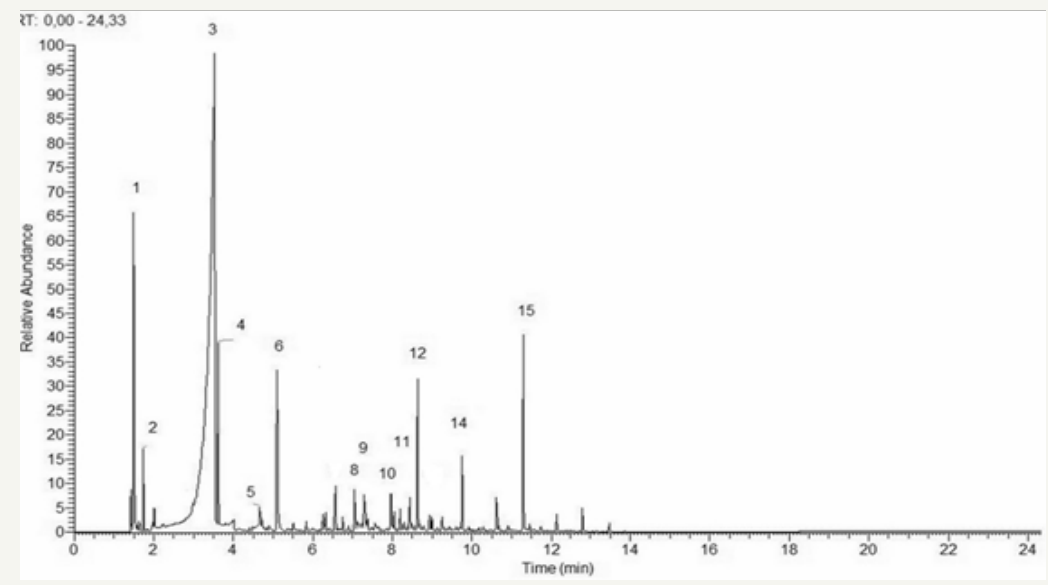

Figure 5: Chromatogram of distillate pyroligneous liquor- Group 1- PDS.

Chromatogram of distillate pyroligneous liquor-PDS. The numbers on the peaks correspond to the chemical components listed in (Table 2).

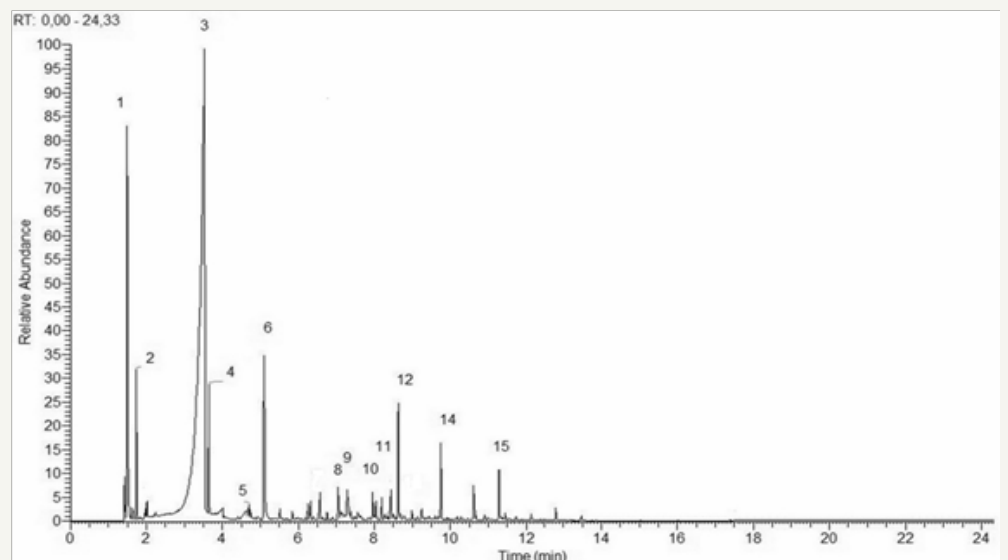

Figure 6: Chromatogram of distillate pyroligneous liquor-Group 2-PDC.

Chromatogram of distillate pyroligneous liquor-PDC. The numbers on the peaks correspond to the chemical components listed in (Table 2). 


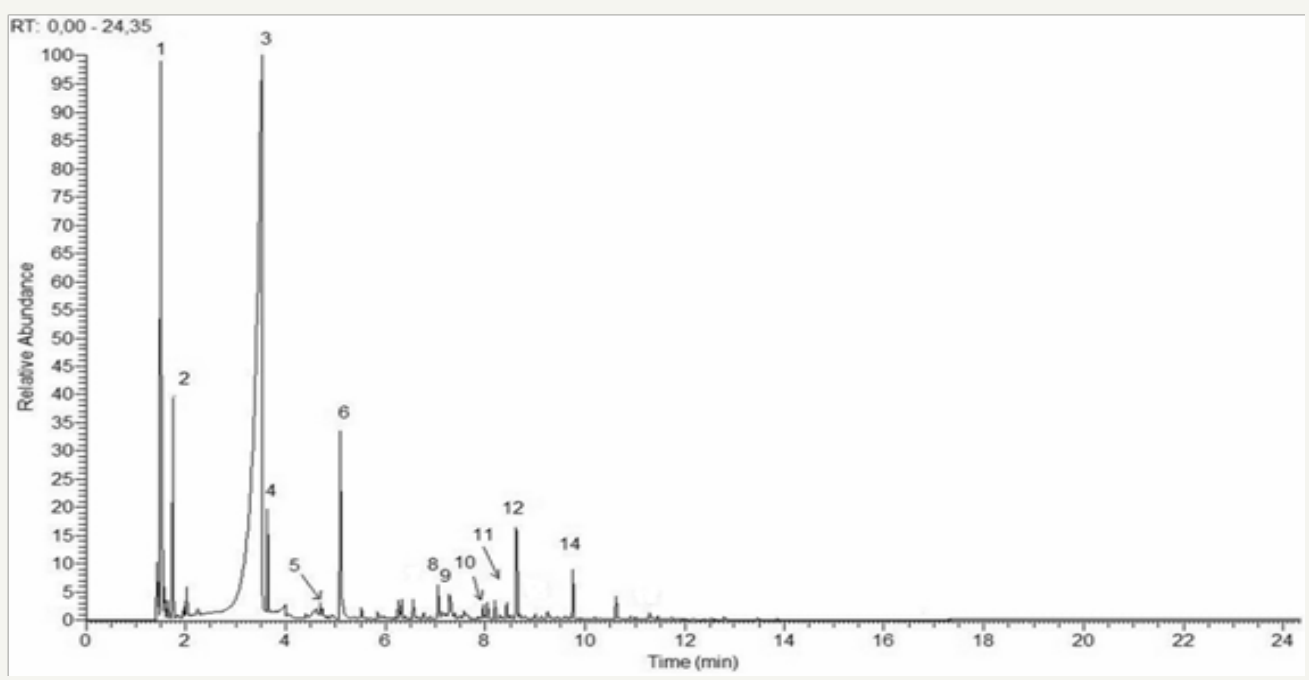

Figure 7: Chromatogram of distillate pyroligneous liquor -Group 3- PDCC.

Chromatogram of distillate pyroligneous liquor-PDCC. The numbers on the peaks correspond to the chemical components listed in (Table 2).

These chemical composition differences were occasioned by the distillation process adopted that separates the components from liquid through vaporization and condensation, based on different volatility (vaporization point) of the components in the mixture and the activated charcoal used that should selectively removed toxins due the highly porous charcoal. In summary, the changes in pyroligneous liquor composition could be explained by the separation and purification process that may led to fewer chemical tar components. The Group 3 corresponded to the most effective process for removing one of the most toxic compounds from the pyroligneous liquors: the 2,6-dimetoxyphenol. This compound is very hazardous on skin contact, ingestion and inhalation [8].

\section{Conclusion}

In general, the results showed that pyroligneous liquor from eucalyptus wood, independent of the process, possesses a series of chemical compounds such as carboxylic acids, ketenes, phenols, furans, alkanes, alkenes and polycyclic aromatic hydrocarbons. The compounds butyrolactone and maltol, present in original pyroligneous liquors, were not found in the distilled liquors of the other experimental groups. Through the qualitative evaluation, it can be noticed that Group-3 distillation had the highest influence on the chemical composition of the obtained product and it was the most efficient for removal one of the toxic substance from the pyroligneous liquor: the 2,6-dimetoxyphenol. Regarding the gravimetric yield, no significant differences between the distillation processes were observed.

\section{References}

1. Oliveira M (2011) Carvão vegetal sustentável. Pesquisa Fapesp 189.

2. Pimenta AS, Bayona JM, Ramón TG, Cánovas AMS (2013) Evaluation of acute toxicity and genotoxicity of liquid products from pyrolisis of Eucalyptus grandis Wood. Archives of environmental contamination and toxicology 38(2): 169-175

3. Cristale J, Silva FS, Marchi MRR (2008) Development and application of GC-MS/MS method for simultaneous analysis of 17 PAHs in airborne particulate matter. Eclética Química 33(4): 69-71.

4. São Paulo (2003) Associação dos produtores de agricultura natural. Produção e padronização de extratos pirolenhosos da APAN, Brazil, p:11.

5. Esteves B, Graça J, Pereira H (2008) Extractive composition and summative chemical analysis of thermally treated eucalypt wood. Holzforschung 62(3): 344-351.

6. Martins AF, Diniz J, Stahl JA, Cardoso AL (2007) Characterization of liquid products and char from the pyrolysis of eucalyptus sawdust. Química Nova 30(4): 873-878.

7. Ratanapisit J, Apiraksakul S, Rerngnarng A, Chungsiriporn J, Bunyakarn C (2009) Preliminary evaluation of production and characterization of wood vinegar from rubber wood. Ongklanakarin Journal of Science and Technology 31(3): 343-349.

8. Sigma Aldrich (2012) Material Safety Datasheet-MSDS-2,6Dimethoxyphenol. Sciencelab.com, USA.

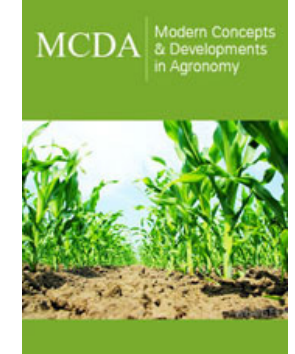

\section{Modern Concepts \& Developments in Agronomy}

\section{Benefits of Publishing with us}

- High-level peer review and editorial services

- Freely accessible online immediately upon publication

- Authors retain the copyright to their work

- Licensing it under a Creative Commons license

- Visibility through different online platforms 